\title{
Contribuições da Psicanálise Existencial à Prática Clínica: Indicações
}

\section{Teóricas e Metodológicas}

\author{
Fernando Gastal de Castro* \\ Universidade Federal do Rio de Janeiro - UFRJ, Rio de Janeiro, RJ, Brasil \\ ORCID: https://orcid.org/0000-0003-0200-9175 \\ André Diogo Resende** \\ Universidade Federal do Rio de Janeiro - UFRJ, Rio de Janeiro, RJ, Brasil \\ ORCID: https://orcid.org/0000-0002-6108-8654 \\ Mariana Gabriel**** \\ Universidade Federal do Rio de Janeiro - UFRJ, Rio de Janeiro, RJ, Brasil \\ ORCID: https://orcid.org/0000-0001-7378-3841
}

\section{RESUMO}

Tem-se como objetivo desse artigo aportar contribuições teóricas e metodológicas da psicanálise existencial à prática clínica a partir do existencialismo e da fenomenologia de Jean-Paul Sartre. Em um primeiro momento, esboçaremos os contornos principais da psicanálise existencial em comparação com a perspectiva freudiana, focando nos conceitos de desejo, projeto, repressão e situação, sustentando a psicanálise existencial como uma clínica de situações. Em um momento seguinte, nos dedicamos à exposição de um caso clínico, com a finalidade de tornar mais concreta as contribuições metodológicas do método progressivoregressivo e da reflexão purificadora. Buscaremos mostrar, nesse sentido, a pertinência de uma perspectiva metodológica que alcance o vivido singular, atravessado pelas múltiplas formas de violências do universo social produtoras de situações traumáticas, bem como as possibilidades de metamorfose do projeto existencial. Em nossas considerações finais, destacamos os desafios de uma prática clínica em se ocupar da dialética entre o universo social, no qual recrudescem formas de violência, e a singularidade do projeto existencial em luta contra suas determinações e desejoso por transformar-se.

Palavras-chave: psicanálise existencial, clínica de situações, existencialismo, fenomenologia.

\section{Contributions of Existential Psychoanalysis to Clinical Practice:}

\section{Theoretical and Methodological Indications}

\begin{abstract}
The aim of this article is to contribute theoretical and methodological contributions from existential psychoanalysis to clinical practice based on Jean-Paul Sartre's existentialism and phenomenology. At first, we will lay out the main outlines of existential psychoanalysis in
\end{abstract}


comparison with the Freudian perspective, focusing on the concepts of desire, project, repression and situation, supporting existential psychoanalysis as a clinic of situations. Subsequently, we dedicate ourselves to the presentation of a clinical case, in order to make the methodological contributions of the progressive-regressive method and purifying reflection more concrete. We will try to show, in this sense, the pertinence of a methodological perspective that reaches the singular lived, crossed by the multiple forms of violence of the social universe that produce traumatic situations, as well as the possibilities of metamorphosis of the existential project. In our final remarks, we highlight the challenges of a clinical practice in dealing with the dialectic between the social universe, in which forms of violence increase, and the uniqueness of the existential project in the fight against its determinations and eager to transform itself.

Keywords: existential psychoanalysis, clinic of situations, existentialism, phenomenology.

\title{
Contribuciones del Psicoanálisis Existencial a la Práctica Clínica:
}

\section{Indicaciones Teóricas y Metodológicas}

\begin{abstract}
RESUMEN
El objetivo de este artículo es aportar contribuciones teóricas y metodológicas desde el psicoanálisis existencial a la práctica clínica a partir del existencialismo y fenomenología de Jean-Paul Sartre. En primer lugar, trazaremos los principales trazos del psicoanálisis existencial en comparación con la perspectiva freudiana, centrándonos en los conceptos de deseo, proyecto, represión y situación, apoyando el psicoanálisis existencial como clínica de situaciones. En un momento siguiente, nos dedicamos a la presentación de un caso clínico, con el fin de concretar los aportes metodológicos del método progresivo-regresivo y la reflexión depuradora. Intentaremos mostrar, en este sentido, la pertinencia de una perspectiva metodológica que llegue a lo singular vivido, atravesado por las múltiples formas de violencia del universo social que producen situaciones traumáticas, así como las posibilidades de metamorfosis del proyecto existencial. En nuestro comentario final, destacamos los desafíos de una práctica clínica en el abordaje de la dialéctica entre el universo social, en el que aumentan las formas de violencia, y la singularidad del proyecto existencial en la lucha contra sus determinaciones y deseoso por transformarse.
\end{abstract}

Palabras clave: psicoanálisis existencial, clínica de situaciones, existencialismo, fenomenología.

Tem-se como objetivo desse artigo aportar contribuições teóricas e metodológicas da psicanálise existencial à prática clínica a partir do existencialismo e da fenomenologia conforme desenvolvidos por Jean-Paul Sartre. Diferentemente da psicanálise freudiana que nasce da prática clínica, a psicanálise existencial emerge como proposta teórica e metodológica no âmbito da filosofia e, mais especificamente, ao final do ensaio da ontologia 
fenomenológica de J-P Sartre (1996). Os desafios, portanto, que se colocam para a prática clínica que busca desenvolver-se a partir de tais matrizes filosóficas, são de articular os conceitos com os fenômenos subjetivos de maneira a escapar da abstração filosófica por um lado e do empirismo pobre teoricamente por outro.

A fenomenologia desenvolvida por Sartre ganha sua especificidade ao incorporar, como sustenta Seel (1995), a dialética, permitindo articulações inovadoras entre o método fenomenológico e o método progressivo regressivo. Nesse sentido, uma prática clínica, que toma como seu objeto os projetos existenciais (Castro \& Ehrlich, 2016), necessita apreender a totalização em curso das escolhas humanas a partir de dois pontos de vista simultâneos: a interiorização do exterior - o universo social e suas determinações alienantes - e a exteriorização do interior - a liberdade projetante forjando seus próprios possíveis (Alvim \& Castro, 2015).

Buscar-se-á, dessa maneira, na primeira parte deste trabalho desenvolver os conceitos de projeto, desejo, repressão e situação, sustentando a ideia da psicanálise existencial como clínica de situações (Alvim \& Castro, 2015). Na segunda parte, nos dedicaremos aos aportes metodológicos pertinentes à prática clínica e que, conforme sustentamos, permitem ver e fazer ver os desvios alienantes dos projetos existenciais em uma sociedade determinada pela exploração e pela violência (Sartre, 1960), bem como a liberdade do para si em luta contra sua situação, buscando transformar-se.

\section{Psicanálise Existencial e Clínica de Situações}

Sartre é um filósofo que, desde suas primeiras obras, se interessa pela psicanálise. Em suas obras iniciais, quando se ocupa do desenvolvimento de uma psicologia fenomenológica afirma com Freud que a realidade humana é afeto (Sartre, 2010). Porém, diferentemente do freudismo, sustenta que a significação da vida afetiva não pode ser tributária de um sujeito inconsciente de si, mas, remeter-se à existência intencional e consciente em seu movimento de transcendência em direção ao mundo social e material, formando com as coisas e os outros uma unidade sintética indissolúvel. No mesmo sentido, encontramos em várias partes de $O$ ser e o nada (Sartre,1996) a problematização de conceitos freudianos fundamentais, que permitem ao filósofo avançar na compreensão do caráter significativo das experiências subjetivas. Destacamos aqui dois destes conceitos que, no âmbito deste artigo, adquirem um lugar de destaque, quais sejam: os de desejo e de repressão. 
O fato de a realidade humana ser afeto significa, em primeiro lugar, que é corpo (Sartre, 1996). No entanto, a corporeidade da existência precisa ser diferenciada do corpo tomado como objeto ou ente abstrato que envolveria dentro de si a substância psíquica, como também do corpo como puro comportamento, desprovido de subjetividade. O corpo aparece, nesse sentido, como dimensão ontológica na qualidade de corpo vivido, ou seja, como corpo que sou e não corpo que tenho (Van den Berg, 1972). Dessa maneira, o desejo como afeto fundamental da existência humana (Sartre, 1996) caracteriza-se como corpo desejante, fazendo da corporeidade e seus desejos uma mesma unidade.

O ser humano, dessa maneira, define-se por ser desejos (Sartre, 1996) o que significa, em consonância com a tese freudiana, que a realidade humana é falta e, ao mesmo tempo, movimento concreto no mundo em direção a sua supressão (Cannon, 1991). A particularidade, porém, da análise sartriana do desejo destaca-se por dois aspectos que a diferenciam de Freud. A primeira delas é dada pela intencionalidade do desejo, que faz com que nossas faltas tenham em um ente transcendente e mundano seu sentido fundamental. Desejar alguém é, portanto, ter consciência irrefletida desse alguém como desejável, o que significa estar falto desse alguém, de sua presença, de seu toque, de seu olhar, de sua implicação na minha existência. Se desejo tomar uma cerveja, sou falto dessa bebida alcoólica, de seu sabor, de seu aroma, da sensação que me proporciona. Em suma, a intencionalidade do desejo, ao implicar a unidade ser faltante - objeto da falta, não nos remete, como na psicanálise freudiana, a um significante inconsciente e abstrato, mas às necessidades concretas do ser no mundo, bem como ao quadro de escassez social-material que as atravessam. O segundo aspecto que diferencia o conceito de desejo em Sartre refere-se a sua estrutura temporal. A falta freudiana resulta do recalque, logo a estrutura temporal do desejo é marcada pela intrínseca conexão de causalidade entre passado e presente (Cannon,1991). Já a falta na ontologia fenomenológica implica a existência do não-ser (futuro) no seio do ser como sua condição originária, o que nos remete a outra estrutura temporal, na qual o desejo remete-se ao ser futuro que sou na forma de não sê-lo (valor) e que se faz, por sua vez, polo unificador das experiências passadas.

Em relação ao conceito de repressão, a ontologia de Sartre lhe reserva, a princípio, um papel secundário no conjunto de suas elaborações teóricas. Porém, quando nos colocamos a tarefa de pensar as contribuições da psicanálise existencial à prática clínica, tal noção ganha uma função de destaque. Consideramos nesse sentido que, em Questões de método (Sartre, 1960), Sartre volta a remeter-se à psicanálise, sublinhando neste novo contexto de diálogo 
com o marxismo a importância de compreender os projetos existenciais em sua totalidade, ou seja, desde a infância:

A psicanálise, no interior de uma totalização dialética, reenvia por um lado as estruturas objetivas às condições materiais e, por outro, a ação de nossa indepassável infância sobre a vida adulta [...] e o existencialismo ajudado pela psicanálise pode estudar somente situações em que o homem perdeu-se desde a infância, pois não há outras em uma sociedade fundada na exploração (Sartre, 1960, pp. 58-59).

A repressão dos desejos humanos comparece aqui, portanto, como fato social total, ou seja, como estrutura social alienante que viola o devir das múltiplas possibilidades humanas, desde a infância, e está na raiz dos projetos existenciais, ou seja, da eleição dos possíveis e de seus desvios. Além disso, o tratamento teórico dado ao conceito de repressão comparece em O ser e o nada quando o filósofo, em diálogo com Freud, sustenta que reprimir implica na consciência de reprimir. Os desvios alienantes, portanto, remetem por um lado tanto às estruturas sociais fundadas na exploração e na disciplinarização dos corpos (Foucault, 1991) como, por outro, à própria consciência singular, que realiza o ato de reprimir as experiências desejáveis, sendo este um momento crucial da totalização dos projetos existenciais e das possibilidades de eleição de si.

A psicanálise existencial comunga, portanto, da tese freudiana de que os significados dos afetos só podem ser compreendidos dentro da totalidade de uma vida singular, sendo a infância e a idade adulta dois momentos de um mesmo processo totalizante. Porém, não é aos destinos das pulsões que Sartre irá encontrar as bases de tal processo, mas sim na complexidade do que designou de escolha original (Sartre, 1996), capaz de dar sentido a um projeto na medida em que realiza certo possível em meio a um campo de possíveis e com este certo valor em meio a um campo estruturado de valores:

O fato de que o termo último dessa investigação existencial deve ser uma escolha diferencia melhor ainda a psicanálise [de Freud] daquela da qual nós esboçamos o método e os traços principais: ela renuncia ao mesmo tempo a supor uma ação mecânica do meio sobre o sujeito considerado (...) o meio somente poderia agir sobre o sujeito na medida em que ele o compreende, quer dizer, quando este se transforma em situação. Nenhuma descrição objetiva desse meio poderia, portanto, nos servir. Desde a origem, o meio conhecido como situação reenvia ao para-si escolhendo, 
exatamente como o para-si reenvia ao meio através de seu ser no mundo (Sartre, 1996, pp. 660).

A investigação dos destinos das escolhas humanas com seus projetos existenciais e as estruturas sociais de opressão apresentam-se, por sua vez, como polos indissociáveis a partir do conceito de situação (Sartre, 1996). Nesse sentido, somente a razão dialética (Sartre, 1960) mostra-se capaz de dar compreensibilidade à existência em sua tensão entre o para-si unificante do seu campo prático a partir de suas escolhas e a facticidade social e material com o peso de suas determinações:

Se alguma coisa, em efeito, deve existir como unidade sintética do diverso, somente pode tratar-se de uma unificação em curso, quer dizer, de um ato (...) Assim, a dialética é atividade totalizadora, e não há outras leis que as regras produzidas pela totalização em curso e esta concerne evidentemente às relações de unificação do unificado, quer dizer, aos modos de presença eficaz do devir totalizante em relação às partes totalizadas (Sartre, 1960, pp. 163-64).

O conceito de situação representa pois, dentro desse quadro, a dialética da unidade sintética do diverso realizada pela atividade totalizadora de um projeto existencial singular. De sorte que o diverso nos remete às determinações sociais e materiais próprias à certa classe social e às estruturas raciais, familiares, laborais ou de gênero próprias de uma situação. Já a unidade sintética desse diverso, somente ganha esse status em função da presença eficaz do devir totalizante, ou seja, dos atos humanos que se projetam em direção à diversidade social e material, ou seja, em direção ao campo de possíveis e seu valor. Encontramos aqui a dialética do universal e do singular no sentido de que:

Um homem nunca é um indivíduo; seria melhor chamá-lo de universal-singular: totalizado e, por isso mesmo, universalizado por sua época, ele a retotaliza ao se reproduzir nela como singularidade. Universal pela universalidade singular da história humana, singular pela singularidade universalizante de seus projetos, ele exige ser estudado a um só tempo pelas duas pontas (Sartre, 1972, pp. 7).

Logo, a psicanálise existencial tem como seu objeto os projetos existenciais enquanto totalização em curso de uma eleição original (Castro \& Ehrlich, 2016), com seus desvios 
alienantes e seus impasses. No entanto, as estruturas subjetivas desta totalização e sua compreensão em profundidade não devem nos remeter a um sujeito meta-empírico inconsciente, mas à dialética entre as determinações alienantes de uma sociedade fundada na exploração do homem pelo homem e a liberdade como síntese permanente dessas determinações (Castro, 2017a). Nesse sentido, por ser justamente a razão dialética a inteligibilidade das experiências totalizantes (Sartre, 1960) e, por tais experiências estarem no centro da vida humana e de seus projetos existenciais, nos parece pertinente conceber a psicanálise existencial como uma clínica de situações:

Podemos estabelecer, desta maneira, um esboço daquilo que definimos como Clínica de Situações. É o esforço prático e teórico em direção à subjetividade singularizandose como projeto em meio às dimensões espaciais do ser de classe e das dimensões temporais do passado e da morte. A partir disso, sublinhamos a importância capital da atividade clínica desvincular-se da subjetividade hipostasiada, abstraída da objetividade e de suas determinações espaciais e temporais. Além disso, uma clínica de situações, tal como buscamos sustentar, requer uma perspectiva concreta a fim de evitar aquilo que Sartre chama de perspectiva de sobrevoo (Sartre, 1960), que aborda a situação de um ponto de vista genérico e abstrato. Meu lugar, meus arredores, meu próximo, meu passado e minha morte formam um conjunto sintético, singular e concreto de determinações próprias de minha classe e das significações sociais do tempo presente em que me encontro (Castro, 2019a, pp. 245).

Desta maneira, os caminhos para construção de uma prática clínica baseada na psicanálise existencial nos remetem a uma perspectiva metodológica capaz de ocupar-se tanto da análise dos acontecimentos concretos de uma vida singular, bem como da síntese totalizante do diverso operada pelo sujeito o que, por sua vez, nos reenvia ao método progressivo-regressivo (Sartre, 1960), como hodos mais apropriado à viabilização de uma clínica situada. A fim de avançar na função fundamental do método progressivo-regressivo para a prática clínica nos valeremos a seguir de um caso clínico. Nosso propósito se concentrará, nesse sentido, em explorar e compreender o mal-estar e o projeto existencial de Ariana a partir das possibilidades do método sartreano como forma de concretização das categorias teóricas discutidas até o momento. 


\section{O caso de Ariana a1}

\section{Situação atual e impasse}

O método progressivo-regressivo, conforme enunciado em Questões de método (1960), exige que "a mais rudimentar conduta seja determinada simultaneamente em relação aos fatores reais que a condicionam e a um certo objetivo futuro que ela procura engendrar" (Laing, 1982, p. 37). Sartre, nesse sentido, em consonância com o marxista Henri Lefebvre, sustenta três momentos essenciais de seu método: um primeiro momento de descrição fenomenológica, que busca alçar a particularidade da experiencia fenomênica tal como ela é vivida. Em seguida de dois outros momentos metodológicos que se alternam em um vai e vem constante, quais sejam: o momento analítico-regressivo, que se ocupa da relação presentepassado, e o momento progressivo-sintético, que visa apreender a relação presente-futuro. Buscaremos a seguir dar compreensibilidade a tal método a partir da exploração do caso clínico de Ariana.

Ariana busca atendimento psicológico por estar vivendo fortes crises de ansiedade após a tentativa de suicídio de sua mãe, que se somava ao peso de ter um pai diagnosticado como paciente psiquiátrico desde sua tenra infância. Ariana não estava mais suportando a presença da loucura no seio de sua família. Sua infância foi permeada por surtos psicóticos paternos, com intenções homicidas e suicidas, fato esse que levou à separação dos pais. Ariana, desse modo, cresceu sem a presença do pai, sendo seu núcleo familiar formado unicamente por ela e sua mãe que, por sua vez, mostrou-se ao longo da vida da paciente sofrendo com um humor depressivo e dependente de medicamentos psicotrópicos, sendo mais de uma vez afastada do trabalho por razões emocionais.

$\mathrm{O}$ primeiro aspecto metodológico que convém destacar diz respeito à descrição fenomenológica da situação presente (Castro, 2019a) como primeiro momento do trabalho psicoterapêutico. Trata-se, nesse aspecto, da exploração das experiências desejáveis e suas repressões alienantes, dentro do conjunto das relações atuais do sujeito, de forma a proporcionar uma primeira apreensão sintética do seu ser no mundo nas circunstâncias em que se encontra ao começo do trabalho clínico. Tal descrição da situação atual tem por objetivo alcançar os núcleos de sofrimento e de desejo da pessoa concreta, ou seja, o conjunto de afetos que configuram seu ser no mundo no aqui e agora presente.

Nesse sentido, destaca-se primeiramente, no caso de Ariana, sofrimento familiar que, embora permeie o conjunto de sua história, apresenta-se, em função da tentativa de suicídio 
materna, um importante desencadeador das crises de ansiedade que a levaram a procurar ajuda psicológica. Dois aspectos mostram-se importantes de serem considerados quanto à característica da descrição fenomenológica das experiências de sofrimento: sua intencionalidade e sua amplitude. Para Ariana, a tentativa de suicídio materna a coloca face à presença incontornável do enlouquecimento, do desequilíbrio, da falta de controle emocional, da vida inviabilizada e dependente de medicações e tratamentos psiquiátricos e dos surtos psicóticos do pai que a acompanhavam desde sua infância. As crises de ansiedade, que se desencadeiam em função da tentativa de suicídio de sua mãe possuem, desse modo, uma intencionalidade constituída pela consciência de ser aquela que viverá surtos psicóticos como o pai, que será deprimida e dependente como a mãe e que, enfim, não será capaz de realizar qualquer desejo próprio em função do destino familiar lhe atravessar a existência. Uma consciência destino parece ser o que melhor expressa o tipo de intencionalidade que permeia suas crises de ansiedade, fazendo da vivência do sofrimento familiar algo que habita sua situação presente de forma perturbadora.

Outro aspecto da descrição do sofrimento a ser considerado, como dissemos, é sua amplitude. O sofrimento vivido pelas crises de ansiedade restringe-se à relação com os pais ou transcende essa relação e se faz presente noutros lugares que habita para além da família? A exploração fenomenológica deste núcleo de sofrimento permitiu ver e fazer ver que a situação vivida no âmbito familiar reverbera para vários domínios de existência de Ariana. Diante de relações amorosas, vive crises de ansiedade similares quando percebe algum risco de ruptura afetiva; as mesmas crises se reproduzem quando está na universidade e teme não ser aprovada, sentindo-se presa à mesma consciência destino da situação familiar.

Além da descrição fenomenológica das experiências de sofrimento, faz-se também necessário, para uma apreensão sintética do conjunto da situação atual do sujeito, a descrição de seus núcleos de desejo. Nesse sentido, observou-se que para Ariana, a faculdade de fonoaudiologia faz-se não somente uma experiência de sofrimento, mas também um objeto desejado. Ariana sente a falta de sair-se bem nas matérias e tirar boas notas, sente a falta de ter o diploma e ser fonoaudióloga, bem como a falta de ser alguém para além da facticidade da loucura familiar. Outro objeto de desejo identificado pela descrição fenomenológica diz respeito ao relacionamento amoroso. De forma similar ao que é vivido em relação à faculdade, o relacionamento amoroso é perpassado não somente pelas crises de ansiedade, mas pelo desejo de construir uma vida junto com seu namorado, habitar com ele o mesmo lugar, compartilhar o prazer pelo teatro, pela música e pelas viagens. 
Desta descrição das experiencias de sofrimento e desejo surge uma primeira apreensão sintética do sujeito em situação. Ariana vê e é vista no conjunto de seu ser, presentificando o sentido de seus sofrimentos e de seus desejos. Compreende, dessa maneira, a ambiguidade em que se encontra: condenada à consciência destino para a qual somente lhe resta a loucura, o adoecimento psíquico, a dependência, a vida extraviada, presentifica, ao mesmo tempo, a luta que realiza contra si mesma e sua situação familiar, forjando um contradestino através da faculdade e do relacionamento amoroso e sentindo, mesmo que contraditoriamente, o gosto de outro possível para si. Temos aqui uma situação de impasse, na qual os termos antagônicos se constituem, ao mesmo tempo, como complementares e incompatíveis. Quanto mais luta pelo desejo amoroso e profissional, mais é assombrada pela loucura, pela doença e pela inviabilização da vida que aparecem como sua força repressiva a inviabilizar os possíveis desejados. Por outro lado, quanto mais se vê enredada e capturada pela loucura familiar, mais luta para sair dela. Repetição e luta contra a repetição, violência repressiva e força desejante formam, assim, uma unidade dialética de opostos que se retroalimentam.

\section{Situação traumática e Projeto: Regressão à Histórica e Síntese Progressiva}

A partir da apreensão sintética do impasse, fruto da descrição fenomenológica da situação atual, sustentamos que uma prática clínica deve orientar-se por um movimento analítico regressivo em direção à situação traumática e por um movimento progressivo sintético em direção à síntese operada pelo projeto existencial e suas contradições.

Alcançar uma situação traumática implica, em primeiro lugar, ultrapassar os limites da reflexão impura (Mendes-Campos \& Barata, 2017) própria da temporalidade psíquica, tão comum nas queixas psicológicas que afirmam eu sou assim e não de outro jeito. Nesse sentido, a psicanálise existencial lança mão do caminho regressivo caracterizado pela unidade presente-passado visando que o sujeito revivencie a experiência de impasse na medida em que este se presentifica e concretiza pela mediação da prática clínica. O objetivo visado é o desvelamento do sentido da ação em meio às determinações da situação em que se encontra o sujeito, vendo e fazendo ver a verdade existencial de seu impasse. A exploração regressiva e progressiva de situações traumáticas visa desvelar, dessa maneira, o peso das determinações que alienam a existência concreta e, ao mesmo tempo, como o sujeito projeta-se em direção a seus possíveis e aprisiona-se a certo impasse. 
Retornemos ao caso de Ariana a fim de avançar na compreensão do que estamos designando por situação traumática e sua importância essencial para a perspectiva clínica aqui desenvolvida.

Em uma das sessões, Ariana relata ter vivido uma de suas crises de ansiedade. A descrição fenomenológica revelou a seguinte situação: estava vendo um filme a noite na casa de seu namorado, quando ele fez um comentário sobre o ator Marlon Brando e Ariana confundiu-se-pensando que se tratava de Al Pacino. Ao manifestar ao namorado seu engano, imediatamente condena-se pelo erro cometido e o seu namorado reage com espanto, recriminando Ariana por confundir os atores do clássico filme $O$ poderoso chefão. Nesse momento, o namorado aparece para Ariana como alguém superior, conhecedor de cinema, culto, em contraste com ela, que se experimenta inferior, incapaz de estar à altura dele e de qualquer outro, sentindo-se destinada a ser um nada. A crise emocional é vivida como uma tempestade de pensamentos negativos sobre si, acompanhados de um choro descontrolado. Ariana constata-se, a partir da descrição fenomenológica da situação, alguém vazia, confinada a cuidar da mãe, a sofrer com as mesmas enfermidades e cativa de um horizonte futuro de repetição da loucura familiar.

Tal pavor que habita seu horizonte futuro com a loucura e o adoecimento faz-se objeto essencial tanto da análise regressiva, que enfatiza o peso das determinações de sua histórica e dos acontecimentos familiares, como também da síntese progressiva, que visa apreender como seu projeto sintetiza sua histórica em direção ao futuro, permitindo ver e fazer ver a dinâmica temporal em curso e seu impasse. Nesse sentido, outra crise de ansiedade trabalhada em sessão psicoterapêutica irá nos permitir avançar um pouco mais na compreensão do que estamos designando por situação traumática, assim como sua função no desvelamento do projeto vivido. Ariana, em dado momento, compreende que seu relacionamento amoroso era abusivo e decide terminá-lo. Vai então ao encontro do namorado comunicar sua posição. Ao encontrar-se na rua, em frente ao prédio onde ele morava e prestes a tocar o interfone, sua mão paralisa e vive outra crise. Seu coração palpita muito rápido, sente tontura e falta de ar e uma sensação de vertigem.

A análise regressiva revela que tocar o interfone, subir e comunicar ao namorado o término do relacionamento constitui-se um ato carregado por um intenso objeto emocionador (Sartre, 2010). Seu sentido se presentifica à paciente como sendo o horizonte futuro que se desvela pelo ato de terminar o namoro, futuro esse habitado pela certeza de que ficará sozinha ao lado da mãe indefinidamente, sufocada por suas demandas, restando-lhe à morte em vida e o desespero do enlouquecimento. Além disso, a exploração sintético progressiva da situação 
revela também que renunciar ao relacionamento amoroso, embora permeado por conflitos e momentos abusivos, mostra-se para Ariana extremamente difícil, visto ter sido com ele que, pela primeira vez, descobriu a possibilidade de ser outra para além das determinações familiares, desejando e sendo desejada, amando e sendo amada e, enfim, compartilhando um mundo comum permeado pelo cinema, pelo teatro e pelas viagens.

Ariana depara-se com sua situação traumática: revive com todo seu corpo as determinações familiares, a força das injunções maternas que sempre a rebaixaram, a anularam, a humilharam, somadas ao peso da loucura (paterna-materna), como repetição de um passado indepassável. Ao mesmo tempo, sente a força do desejo de ser outra, que lhe aparece não somente como uma falta fundamental a ser preenchida, mas como movimento concreto em curso, que realiza outra possibilidade de ser no mundo. Apertar o botão do interfone para terminar o namoro é volver a situação insuportável de desamparo familiar, sozinha na sua dor, sem nenhum acalanto. O pavor da loucura, do adoecimento psíquico e da invalidez presentificam-se como força determinante de sua infância, definida como a protohistória do sujeito (Sartre, 1972), que totaliza desde fora suas possibilidades de ser. Contraditoriamente, o desejo de ser outra desvela-se como possível para si, ou seja, como não-ser (futuro) capaz de fazer mover a metamorfose presente.

De sorte que a noção de situação traumática que sustentamos como compatível à psicanálise existencial, como clínica de situações, aparece constituída pela unidade totalizante de um projeto existencial e não restrita às determinações familiares ou sócio-materiais. A proto-história a 2 de Ariana está povoada por determinações alienantes, capaz de produzirem a repressão e o desvio a toda ordem de possíveis desejados que, desde a infância, tenha descoberto para si. No entanto, é totalizando as determinações familiares da loucura, do adoecimento psíquico, da psiquiatrização, da invalidez, das humilhações e rebaixamentos que Ariana forjará seus possíveis e o valor unificante de seu projeto. Nesse sentido, ao mesmo tempo que se projeta para ser uma morta em vida que, por sua vez, representa o fim último de todos os seus esforços e todas as suas lutas, Ariana descobre a possibilidade de desejar e ser desejada, dribla o fantasma da loucura e entra para a faculdade a ponto de se fazer alguém desejante pela fonoaudiologia como outra possibilidade de ser no mundo.

A situação traumática constitui-se, portanto, de uma série de acontecimentos violentos vividos desde a infância, oriundos das estruturas familiares e sociais típicas de uma sociedade fundada na exploração que, por sua vez, são unificados pelo para-si em direção a seus possíveis e seu valor. O valor unificante dos possíveis de Ariana aparece, desse modo, como futuro hipostasiado pelo destino de fracasso de todas suas empresas. Ao mesmo tempo, a 
força desse futuro hipostasiado, que nada mais representa do que a reprodução do passado no presente, mostra-se atravessado pela força nadificadora de seu projeto, fazendo nascer uma existência possível em meio a toda ordem de impossibilidades. A situação traumática dessa maneira é a situação de um projeto existencial aprisionado em uma contradição nãodialetizável (Sartre, 1972). Ser e fazer não encontram uma síntese possível visto que, em termos de ser, Ariana é o futuro hipostasiado como destino, dentro de uma ordem de repetição. Porém, em termos de fazer, Ariana é luta contra seu destino e sua práxis, embora sinta a contraforça de uma consciência destino, não se entrega totalmente a ela. Em suma, Ariana é, mas não admite aquilo que é e, por isso, luta para fazer-se outra. Contudo, não consegue ser essa outra, dado o seu assombramento pela loucura que povoa seu futuro e seu passado, dando os contornos de sua situação.

\section{A Função Metodológica da Reflexão Purificadora}

Conforme a ontologia fenomenológica, podemos encontrar dois tipos diferentes de reflexividade. A primeira é designada de reflexão impura (Sartre, 1996) e está na origem da constituição da unidade do Eu com sua temporalidade psíquica. Em suma, é a consciência que afira um ser ao invés de um possível. Eu sou tímido, eu sou inteligente, eu sou desajeitado etc., mostram-se, desta forma, unidades sintéticas de experiências passadas que a reflexividade impura constitui dando forma a certo ser que sou. Para Ariana, eu sou um nada, uma inferior e incapaz evidenciam unidades psíquicas constituídas por uma reflexão que, ao se voltar sobre suas experiências irrefletidas (Castro \& Ehrlich, 2016) de violência, humilhação e de enlouquecimento familiar, afirma a inferioridade e a incapacidade, como estados psíquicos mais ou menos permanentes, que habitam seu passado, seu presente e seu futuro. De sorte que o projeto existencial de Ariana, orientado para o fim último e hipostasiado de ser uma morta em vida e, ao mesmo tempo, pela luta contra ele, vai ao longo de sua história cristalizando uma unidade psíquica que afirma, a cada novo malogro, uma certeza sobre si mesma, que confirma que é mesmo um nada, uma inferior e uma incapaz.

O segundo tipo de reflexividade Sartre (1996) designa de reflexão purificadora. Nesta, o ato de tomar consciência de si alcança a experiência irrefletida na sua temporalidade mais originária própria do para-si. Para além da temporalidade psíquica constituída, a reflexão purificadora revela a experiência presente aberta a futuros possíveis, permitindo, nesse sentido, uma síntese entre fazer e ser que a reflexão impura impossibilita. Vejamos como o caso de Ariana pode nos deixar isso mais compreensível. 
Ariana relata um momento vivido com seu namorado em que descobre que ele havia tido relações sexuais com outra mulher. Ao presentificar esta situação vivida, Ariana ao invés de viver uma nova crise de ansiedade, como regularmente ocorria, sente-se falando com um medroso, inseguro, alguém incapaz de comprometer-se com ela, colocando em dúvida a continuidade do relacionamento. A reflexividade de Ariana, nesse sentido, toma consciência da experiência de traição e desgosto que estava sendo vivida, interrogando-se: por que permanecer com ele?; será que não tenho o direito de ter minha vida sem ele?; por que não posso viajar sozinha?. A descrição fenomenológica da situação revela um sentimento de angústia frente às possibilidades novas que se abrem, na medida em que Ariana vê o que poderia ter sido e não foi até aquele instante. Na sequência, decide fazer seu passaporte, começando a imaginar possíveis lugares para conhecer e pensando em que amigas poderia convidar.

Ariana realiza, neste momento, uma reflexão purificadora. Apreende a própria experiência imediata de traição e desgosto pelo namorado não mais a partir de uma ordem de repetição dada pela reflexividade impura, mas a partir de uma temporalidade originária, origem de uma possibilidade de ser, não de repetição de um ser. A tensão dialética entre fazer e ser encontra desse modo uma síntese possível na medida em que a reflexão purificadora a permite compreender-se como um ser de possíveis e capaz de fazer-se ser. Para a psicanálise existencial, tais momentos de metamorfose do projeto definem-se pelo que Sartre (1996) denomina de instante. Um acontecimento antropológico de compreensão de si na ordem da práxis, no qual o para-si intui um novo horizonte de possíveis e um novo valor e, portanto, instaura outro processo temporalizante. $\mathrm{O}$ instante ocorre na vida prática do sujeito e se caracteriza por um movimento de retotalização do projeto original. Implica, nesse sentido, um tipo novo de compreensão de si resultante da reflexão purificadora que alcança a totalidade constituída do projeto original e, ao mesmo tempo, a possibilidade de uma nova totalização. Ariana age em direção a fazer seu passaporte, imagina lugares possíveis para conhecer, pensa em que amigas convidar. Consegue, dessa forma, ultrapassar a petrificação de seu ser para o outro que desde sua proto-história a rebaixava à dependência, à nulidade e ao fantasma do enlouquecimento. $\mathrm{O}$ instante é um novo presente que se caracteriza por um fim e por um começo (Sartre, 1996), uma modificação profunda no projeto existencial que até então unificava sem cessar sua situação traumática, dando origem a um novo campo de possíveis. Tal metamorfose, convém destacar, não se reduz a um ato isolado, mas desenha um novo processo temporal e, por isso, vem acompanhada de angústia, na medida em que o sujeito 
vive a experiência da liberdade diante daquilo que foi e não quer mais ser e diante daquilo que não é ainda mas se possibilita.

\section{Considerações Finais}

Tratamos ao longo deste artigo de desenvolver algumas contribuições da psicanálise existencial à prática clínica. Na medida em que a psicanálise existencial toma como seu objeto a dialética subjetividade-objetividade dos projetos existenciais, os desafios à prática clínica nos parecem ser o desenvolvimento de contribuições teóricas e metodológicas que permitam ultrapassar a petrificação da temporalidade psíquica resultantes da repressão violenta a que os seres humanos estão sujeitos desde a infância. Vemos, nesse sentido, a importância da tese sartriana sustentada em Questões de Método (1960), quando diz ser o marxismo a filosofia de nossa época o que, para os objetivos desse artigo, significa afirmar, com Jaboby (1975) e Marcuse (1975), a impossibilidade de uma psicanálise fora das determinações históricas da sociedade da mercadoria. A lógica mercantil da mercadoria e do dinheiro, os conflitos de classe, as relações sociais mediadas pelo sistema de mercado, os imperativos do patriarcado moderno próprios à família burguesa, a ética protestante e as determinações do trabalho assalariado, a lógica racial e colonial do ideário iluminista, a moral de seriedade (Sartre, 1983) e a essencialidade da ciência e da técnica com seu ideal de progresso configuram-se, nesse sentido, como determinações incontornáveis de nosso tempo histórico (Castro, 2020) capazes de petrificar a temporalidade da existência em formas passadas dentro de uma ordem de repetição aparentemente insuperável.

A totalização em curso de um projeto existencial, portanto, precisa ser considerada em seu movimento de singularização dentro do tempo histórico do capital (Castro, 2019b) e, ao mesmo tempo, pelo movimento de universalização pelo qual cada um é totalizado pelas forças repressivas e alienantes de nossa época. Nesse sentido, sustentamos que a psicanálise existencial, a fim de evitar o caráter abstrato de uma liberdade desenraizada das determinações do tempo histórico, necessita realizar-se como clínica de situações (Alvim \& Castro, 2015). Uma clínica, portanto, que se oriente pelos princípios do método progressivoregressivo e da reflexão purificadora que possibilite ver e fazer ver os conflitos, os desvios, os impasses, as lutas, os desejos e sua repressão, específicos de um projeto existencial. Acreditamos que as indicações metodológicas sugeridas podem abrir caminhos à uma clínica que seja ao mesmo tempo analítica, ao orientar-se à experiencia concreta com suas formas de 
violências sentidas e cristalizada, bem como sintética ao orientar-se à totalização do projeto em curso e seus impasses.

Nossa contribuição, portanto, dentro dos limites deste artigo, consistiu em mostrar caminhos possíveis para a prática clínica abertos pela psicanálise existencial tanto do ponto de vista teórico quanto metodológico. Dentro de uma sociedade em que recrudescem as formas de violência e exclusão, torna-se, ao nosso ver, cada vez mais pertinente compreender as situações traumáticas às quais a existência se aprisiona como resultantes da tensão dialética entre o projeto singular e as determinações repressivas do universo social vigente, bem como as possibilidades de metamorfoses proporcionadas pela reflexão purificadora.

\section{Referências}

Alvim, M. B. \& Castro, F. G. (Orgs.). (2015). Clínica de situações contemporâneas: Fenomenologia e interdisciplinaridade. Curitiba, PR: Juruá.

Cannon, B. (1991). Sartre \& Psychoanalysis: Na existentialist challenge to clinical metatheory. Kansas: University Press Kansas.

Castro, F. G. (Orgs.). (2017a). J-P. Sartre e os desafios à psicologia contemporânea. Rio de Janeiro, RJ: Via Verita.

Castro, F. G. (2017b). O sofrimento psíquico compreendido na tensão entre má-fé e alienação. In F. G. Castro, D. R. Schneider, \& G. B. J. Boris (Orgs.), J-P. Sartre e os desafios à Psicologia contemporânea (pp. 45-71), Rio de Janeiro: Via Verita.

Castro, F. G. (2019a). Existencialismo, fenomenologia e clínica de situações. In A. M. L. C. Feijoo \& M. B. M. F. Lessa (Orgs.), O gesto fenomenológico: Corpo, afeto e discurso na clínica (pp. 49-60). Rio de Janeiro, RJ: Edições IFEN.

Castro, F. G. (2019b). Marx e o século XXI: Notas para uma teoria crítica da sociedade. Marília, SP: Lutas anticapital.

Castro, F. G. (2020). A subjetividade sem valor: Trabalho e formas subjetivas no tempo histórico capitalista. Curitiba, PR: Appris.

Castro, F. G. \& Ehrlich, I. F. (2016). Introdução à psicanálise existencial: Existencialismo, fenomenologia e projeto de ser. Curitiba, PR: Juruá.

Foucault, M. (1991). Vigiar e Punir: História da violência nas prisões. Petrópolis, Vozes.

Jacoby, R. (1975). Amnésia social: Uma crítica à psicologia conformista de Adler a Laing.

Rio de Janeiro: Zahar.

Laing, R., \& Cooper, D. (1982). Razão e violência. Petrópolis: Vozes. 
Marcuse, H. (1975). Eros e civilização: Uma interpretação filosófica do pensamento de Freud (6a ed.). Rio de Janeiro: Zahar Editores.

Mendes-Campos, C., \& Barata, A. (2017). Discutindo o lugar da reflexão e seus desdobramentos na psicanálise existencial sartriana. In F. G. Castro, D. R. Schneider, \& G. B. J. Boris (Orgs.), J-P. Sartre e os desafios à Psicologia contemporânea (pp. 45-72). Rio de Janeiro, RJ: Via Verita.

Sartre, J-P. (1960). Critique de la raison dialectique: Précédé de Questions de Méthode (Vol. 1). Paris, France: Gallimard.

Sartre, J-P. (1972). L'idiot de la famille: Gustave Flaubert de 1821 a 1857 (Vol. 1). Paris, France: Gallimard.

Sartre, J-P. (1983). Cahiers pour une moral. Paris, Gallimard.

Sartre, J-P. (1996). L’être et le néant: Essai d'ontologie phénoménologique. Paris, France: Gallimard.

Sartre, J-P. (2010). Esquisse d'une théorie des émotions. Paris, France: Hermann.

Seel, G. (1995). La dialectique de Sartre. Lousanne, L'Age d'Homme.

Van den Berg, J. H. (1972). O paciente psiquiátrico: Esboço de psicopatologia fenomenológica. São Paulo, SP: Mestre Jou.

\section{Endereço para correspondência}

\section{Fernando Gastal de Castro}

Rua Nascimento Silva, 48 apto 302, Ipanema, Rio de Janeiro - RJ, Brasil. CEP 22421-022

Endereço eletrônico: fernandogastal@gmail.com

\section{André Diogo Resende}

Rua Voluntários da Pátria, 114 apto 807, Botafogo, Rio de Janeiro - RJ, Brasil. CEP 22270-010

Endereço eletrônico: resende@gmail.com

\section{Mariana Gabriel}

Rua General Canabarro, 71 apto 203, Maracanã, Rio de Janeiro - RJ, Brasil. CEP 20271-202

Endereço eletrônico: marianagabriel.9841@gmail.com

Recebido em: 05/07/2020

Reformulado em: 22/09/2020

Aceito em: 22/09/2020 
Fernando Gastal de Castro, André Diogo Resende, Mariana Gabriel

\section{Notas}

* Prof. Associado do Instituto de Psicologia da Universidade Federal do Rio de Janeiro, membro do Programa de Pós-graduação em Psicologia do Instituto de Psicologia da UFRJ e pesquisador do GT Psicologia e Fenomenologia da ANPEPP.

** Graduando em Psicologia pela UFRJ. Estagia fazendo atendimento clínico na Divisão de Psicologia Aplicada da UFRJ. Faz iniciação científica em Psicologia do Trabalho no IP-UFRJ. Se interessa por fenomenologia e psicanálise existencial.

*** Graduanda em Psicologia pela UFRJ. Estagiou fazendo atendimento clínico na Divisão de Psicologia Aplicada da UFRJ. Estagiou no SUS pelo acadêmico bolsista, atuando no ambulatório. Se interessa por fenomenologia e psicanálise existencial.

${ }^{1} \mathrm{O}$ caso de Ariana é fictício. Foi composto por uma série de fragmentos clínicos de casos atendidos no projeto de estágio em psicoterapia existencialista coordenado pelo professor Fernando Gastal de Castro, na Divisão de Psicologia Aplicada (DPA) da Universidade Federal do Rio de Janeiro. Como afirma Van den Berg (1972) em sua célebre obra $\mathrm{O}$ Paciente Psiquiátrico ao se valer do mesmo recurso, o paciente não sendo ninguém em particular pode evidenciar características de todos.

${ }^{2}$ Definição utilizada por J-P. Sartre em seu livro O idiota da família: Gustave Flaubert de 1821 a 1857 e que designa um momento da infância chamado pelo autor de "constituição" em contraste com a "personalização". Com isso, o filósofo busca dar inteligibilidade à infância como constituída pelo outro como imperativo, por sínteses passivas e pelo peso de ser.

Este artigo de revista Estudos e Pesquisas em Psicologia é licenciado sob uma Licença Creative Commons Atribuição-Não Comercial 3.0 Não Adaptada. 